\title{
Parents at the sport competition: How they react, feel and cope with the event
}

\author{
Rebeka Prosoli ${ }^{1 \mathrm{ABCDE}}$, Marc Lochbaum ${ }^{2,3 \mathrm{ADE}}$, Renata Barić ${ }^{1 \mathrm{ADE}}$ \\ ${ }^{1}$ University of Zagreb, Faculty of Kinesiology (Zagreb, Croatia) \\ ${ }^{2}$ Texas Tech University, Dpt. of Kinesiology and Sport Management (Lubbock, TX, USA) \\ ${ }^{3}$ Education Academy, Vytautas Magnus University (Kaunas, Lithuania)
}

Author contributions: A - Study design; B - Data collection; C - Statistical analysis; D - Manuscript preparation; E Funds collected

\begin{tabular}{|c|c|}
\hline \multicolumn{2}{|l|}{ Abstract } \\
\hline Purpose: & $\begin{array}{l}\text { Researchers rarely focus on documenting parental experiences at sport tournaments. Therefore, our } \\
\text { purpose was to document parent cardiovascular, metabolic and emotional responses to watching their } \\
\text { child compete while also paying attention to their thoughts before and after the competition, levels of } \\
\text { stress, anxiety, depression, and coping strategies. }\end{array}$ \\
\hline Material: & $\begin{array}{l}\text { Parents, a mother and a father of same female adolescent, wore a device made by Firstbeat Technologies } \\
\text { which continuously monitored their heart rate from Thursday evening to Monday evening. The } \\
\text { competition was on Saturday, and it was the taekwondo Croatian National Championships for cadets. } \\
\text { Their child had two fights: she won the first one and lost the second one. Parents completed a number } \\
\text { of questionnaires and two open-ended questions regarding their expectations and overall experience. }\end{array}$ \\
\hline Results: & $\begin{array}{l}\text { Before the contest, dad expected his daughter would fight as best she could while giving her best } \\
\text { effort. The mother hoped that her daughter would pass the first fight. Parents had a similar pattern } \\
\text { of cardiovascular responses to watching their daughter compete but differed in intensity. Emotional } \\
\text { profiles of the mother and father changed several times during the measurement period. Overall, } \\
\text { parent's experienced low levels of stress, anxiety and depression and used numerous strategies to cope } \\
\text { with the event. }\end{array}$ \\
\hline Conclusions: & $\begin{array}{l}\text { Although our research only included one pair of parents it suggests that parents experiences during the } \\
\text { sport events are complex and worth investigating in future research on larger samples. }\end{array}$ \\
\hline Keywords: & \\
\hline
\end{tabular}

\section{Introduction}

Parents play a significant role in their children's attraction to physical activity and their sport participation [1-3]. However, with their child being involved in sport, parents themselves can experience many behavioral, cognitive, and emotional as well as relationship changes [4]. Additionally, they can experience numerous organisational, competitive and developmental stressors $[5,6]$. Transactional theory of stress [7] and Cognitivemotivational-relational theory of stress and emotions [810] are commonly used to investigate stress and coping in sport. Lazarus and Folkman [7] define stress as a relationship between person and environment apprised as reaching or exceeding person's available resources to cope with the demand and therefore represent a threat to its well-being. Coping is defined as investing cognitive and behavioural efforts to deal with the stressors [7]. Research suggested parents use different coping strategies to deal with organizational, competitive and developmental stressors they experience while supporting their child's sport participation [6,11]. Burgess and colleagues [11] conducted research on parents of elite young gymnasts and concluded that they use four categories of coping strategies: detaching from sport, normalization, desire to learn and managing their emotional reactions.

\footnotetext{
(c) Rebeka Prosoli, Marc Lochbaum, Renata Barić, 2021
}

doi:10.15561/26649837.2021.0206
Furthermore, in their study on parents of young British tennis players, Harwood and colleagues [6] used three categories of coping strategies suggested by Nicholls and colleagues [12] to analyse parent's answers to open-ended question: mastery, internal regulation and goal withdrawal. In their research, mastery and internal regulation were more effective in dealing with sport parent's stressors than goal withdrawal, regardless of type of stressor or their appraisal. These are the only two studies that investigated coping with stress of the sports parents even though there are numerous studies on coping of athletes and coaches [13-15]. Furthermore, using effective coping strategies is recognized as important characteristic of successful sport parent [16]. Therefore, we believe there is a need for further investigating parent's sport experiences.

Reactions to stress are not only psychological but physiological as well, one of them being increased heart rate [17]. Heart rate monitors are commonly used in research on athletes $[18,19]$, but have only so far been used in one research on sport parents which used AGT theory framework to explain parent's reactions [20]. Achievement Goal Theory (AGT) [21, 22] describes existence of task or mastery and ego or performance individual goal orientations and motivational climates, with ego/performance orientation emphasizing winning and demonstrating superior ability, and task/mastery orientation emphasizing self-comparison and personal 
improvement. Research finds that task orientation is connected to positive emotions, while ego orientation is connected to negative emotions $[23,24]$ and that creating a task-involving climate resulted in higher positive affect while ego-involving climate procured higher levels of salivary cortisol (stress responsive hormone) and negative affect response [25]. It has been suggested that sport parents should provide unconditional love and support to their young athlete with focus being on effort, not on the result [26]. Young athletes also prefer their parents to be positive, supportive and focused on their effort and attitude [27]. Although there are many positive aspects of parents' involvement in their child's sport and their experiences are not just negative, it is obvious that it can be very demanding to provide adequate level and type of support to the young athlete [28]. Thus, research connecting stress, coping and goal orientations of the sport parents could be useful in further understanding their experiences.

Lazarus [8-10] in his CRMT theory of stress suggested that stress, coping and emotions are connected and should be investigated together. In previous research, sport parents reported feeling intense emotions connected to their child's sport participation [4] [29]. Among other, lack of emotional control and inadequate emotional reactions are identified as problematic sport parents' behaviours $[26,30]$. Therefore, it has been concluded that managing their own emotional reactions is one of the most important skill sport parents should utilize [16]. The Individual Zones of Optimal Functioning (IZOF) model [31] is popular framework for investigating emotions in sport. It suggests there are four global categories of emotion: $\mathrm{P}+$ (pleasant, optimal), $\mathrm{P}-$ (pleasant, dysfunctional), $\mathrm{N}+$ (unpleasant, optimal) and $\mathrm{N}$ - (unpleasant, dysfunctional). Functionally optimal emotions $(\mathrm{P}+, \mathrm{N}+)$ are expected to be higher than dysfunctional ones (P-, N-) during successful performances in sport. To our knowledge, this framework has not yet been used in previous research of sport parents' emotions.

\section{Purpose:}

The purpose of this study was to document parents' emotional, cardiovascular and metabolic reactions before, during and after their child's sport competition. Additionally, we wanted to examine their expectations, overall experience, levels of stress, anxiety and depression as well as coping strategies they use to deal with the event.

\section{Materials and Methods}

\section{Participants}

Two parents participated in this study. They were a mother and a father of the same adolescent female athlete. During data collection, mother was 41 years old, 164 $\mathrm{cm}$ tall and $65 \mathrm{~kg}$ in body weight. Father was 42 years old, $175 \mathrm{~cm}$ tall and $75 \mathrm{~kg}$ in body weight. Parents selfreported their age, body weight and height.

\section{Instruments}

Cardiovascular and metabolic reactions. Parents wore the Firstbeat Technologies Bodyguard 2 device which was continuously monitoring their heart rate. The device was attached to the participant's skin using two chest electrodes.

Emotions. Parents filled the ESP-40 (Emotion State Profile; [32] questionnaire 11 times before, during and after the competition, including before and after each fight. They were given the instruction to think about how they feel regarding their daughter's competition and fill the questionnaire keeping this in mind. The ESP-40 questionnaire consists of 40 items in total, 10 items for each of the IZOF four emotion categories: N- (e.g. tired, sad, upset, distressed, worried), $\mathrm{N}+$ (e.g. tense, dissatisfied, furious, angry, irritated), $\mathrm{P}+$ (e.g. energetic, confident, motivated, certain, enthusiastic), P- (e.g. satisfied, happy, pleased, calm, relaxed). The items are arranged in 10 rows of 4 columns. Participants are asked to rank each item on a four-rank scale within each row, with 4 marking the emotion that describes their experience the best and 1 marking the emotion which describe their experience the least. Total scores are calculated by adding scores within four categories of emotions and can range from 10 to 40 . In this research, we used the Croatian translated version of the ESP-40 questionnaire [33].

Stress, depression and anxiety. To measure parent's levels of stress, depression and anxiety connected to the event we used Depression, Anxiety and Stress Scale (DASS-21) [34]. DASS-21 contains 3 subscales, each measured by 7 items. It is designed to measure symptoms of stress, depression and anxiety. Participants give their answer on a 4 point scale (0-did not apply to me at all; 3-applied to me very much, or most of the time) considering how often they experienced described symptoms during the last week. Result on each subscale is obtained by summing the participant's result on all items of each subscale, with higher results indicating greater levels of stress, depression and anxiety. Results can range from 0 to 21. Alpha reliability levels on previous studies were above .70 [35].

Coping strategies. To measure parent's coping strategies which they used to cope with potential stressors connected to their daughter's competition, we used the Coping with Stress Scale (CSS) [36]. The scale measures 11 coping strategies, each measured with 4 items which makes 44 items in total. The coping strategies are: negotiating (active strategies directed to other people who are connected to the problem or situation; seeking advice and confronting), planning (cognitive efforts directed to finding the solution to the problem), active adapting (taking concrete, practical actions to better deal with the situation), reinterpretation (attempts to see the situation differently and give a stressful situation positive meaning), humour (using humour and looking for a funny aspect of situation), social support (turning to other people and seeking emotional support), expressing emotions (expressing emotions openly), wishful thinking (wishful thinking, fantasizing and wishing for a change or disappearance of stressful situation/stressor), avoiding (cognitive and behavioural actions directed to avoiding situation or escape from it), passivization (accepting the situation; giving up from trying to solve the problem and 
making peace with destiny), fatalism and religion (turning to religion; hoping for help from God, greater force or luck). Cronbach alpha values as reported by the author of the scale [36] were between .41 and .78. We added two more strategies in the questionnaire for this research: smoking/alcohol and exercising, each measured with one item. The participants answered the questions on a scale from 1 (not at all) to 4 (often) regarding how often they used each coping strategy to cope with stressors connected to their daughter's competition.

Expectations and overall experience. To gain better understanding of parents' expectations before the competition, we asked them to fill one open-ended question in the morning on the competition day, before it started: "Please give a short description of your expectations regarding today's competition”. Overall experience was also measured using one open-ended question which parents filled in the evening, after the competition ended: "Please describe your day, give us some thoughts about today's competition, and describe how you felt during today's competition". Both questions were taken from our earlier study on sport parents [20].

\section{Procedure}

After obtaining institutional ethical approval, parents were selected by third author based on their active involvement in their child's sport and knowledge that they will be present during the selected competition (Cadet Taekwondo Croatian National Championship). They both were informed about purpose of the study and consented to participate. The competition was selected based on its importance for the athletes. It was held on Saturday and selected competitor had two fights. She won the first one and lost the second one. Duration of the first fight was 7 min, and second fight was $9 \mathrm{~min}$. Data collection started three days before the competition, on Wednesday, and continued until Monday, two days after the competition.

The Firstbeat Technologies device was put on parents at 21:00 Thursday evening and removed at 21:00 Monday evening, so they wore it for 4 consecutive days. Second author gave the instructions and demonstration about how to use the device on Wednesday. After that, parents themselves put the device on Thursday. Second author was travelling with parents to the competition and was present from Friday to Sunday to support and monitor data collection. Parents were asked to fill the ESP-40 questionnaire once on Wednesday (for demonstration purposes), Thursday and Friday regarding their emotional state connected to upcoming competition. On Saturday, at the competition day, parents filled the ESP-40 questionnaire six times: in the morning before competition, immediately before each of the two fights, immediately after each of the two fights, and in the evening after the competition. In addition, parents filled ESP-40 questionnaire once on Sunday and Monday, after the competition. Furthermore, they answered one open-ended question regarding their expectations for the event at the day of the competition, before it started, and the other open-ended question regarding their overall experience in the evening of the competition day, after it was over. They filled the DASS-
21 and CSS on Monday after the competition keeping in mind their overall experience before, during and after the event.

\section{Data analysis}

In this research data was collected using mixedmethod approach which was previously used in a past sport parents studies [6] [20]. Parent's cardiovascular, metabolic and emotional reactions, levels of stress, anxiety and depression as well as coping strategies were quantitative data. Their expectations for the event as well as their overall experience after the event were qualitative data. All the cardiovascular and metabolic data were analysed using Firstbeat Sport Software. Stress, recovery, cardiovascular and energy expenditure graphs in this study were copied from the reports obtained from Firstbeat Sports Software and Firstbeat Lifestyle Assessment Software.

\section{Results}

\section{Expectations}

On the open-ended questionnaire about the expectations for the upcoming competition, father answered: "I hope she will fight as best as possible and give her best." His answer suggests him having a task goal orientation toward his daughter's competition, with emphasis put on her giving her best and not on the result or comparison to the other athletes. Regarding her expectations for her daughter's competition, mother wrote: "I'm hoping she will pass further. I just want her to pass the first fight." This answer suggests her having a ego goal orientation towards her daughter's competition because she put an emphasis on the result (winning the first fight and continuing the competition).

\section{Cardiovascular and metabolic reactions}

Cardiovascular reactions and energy expenditure of both parents during the competition can be seen in Figure 1 (father), Figure 2 (mother) and Table 1. Parents had similar cardiovascular and energy expenditure patterns during the competition, with the highest values recorded during the second fight (Figure 1 and Figure 2). For the first fight, mother had the strongest reactions at the beginning of the fight and then her HR and energy expenditure dropped towards the end of the fight. Father had the same pattern but his reactions again increased for a short period of time after the fight was over. For the second fight, both parents had almost the same reaction patterns. Their reactions intensified rapidly towards the end of the fight and peaked at the very end, when their daughter was first injured and then lost the fight on golden score. Since they had almost the same minimum resting HR (father $49 \mathrm{bpm}$; mother $48 \mathrm{bpm}$ ), from the Table 1 it is evident that mother had stronger cardiovascular reactions during both fights and the whole event than father did. The Firstbeat device also reported mother having 2 minutes of physical activity and 2 minutes of light physical activity during the first fight, while father experienced 1 minute of physical activity and 6 minutes of light physical activity. During the second fight, device recorded mother having 7 minutes of physical activity and 2 minutes of light 


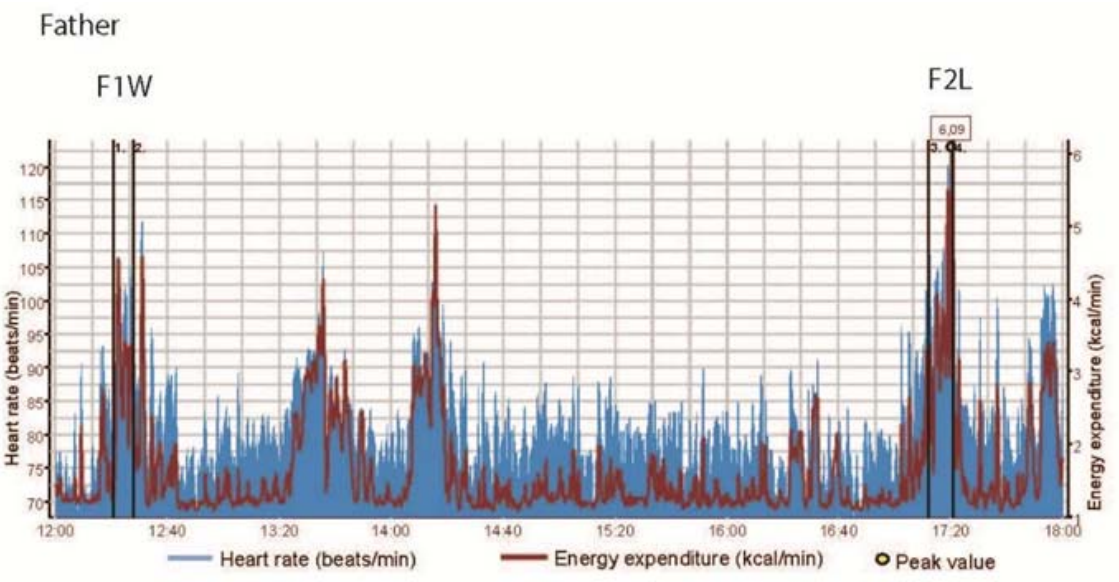

Time

Figure 1. Father's heart rate and energy expenditure graphs during the competition. Time markers F1W-1 ${ }^{\text {st }}$ fight, won; F2L- $2^{\text {nd }}$ fight, lost.

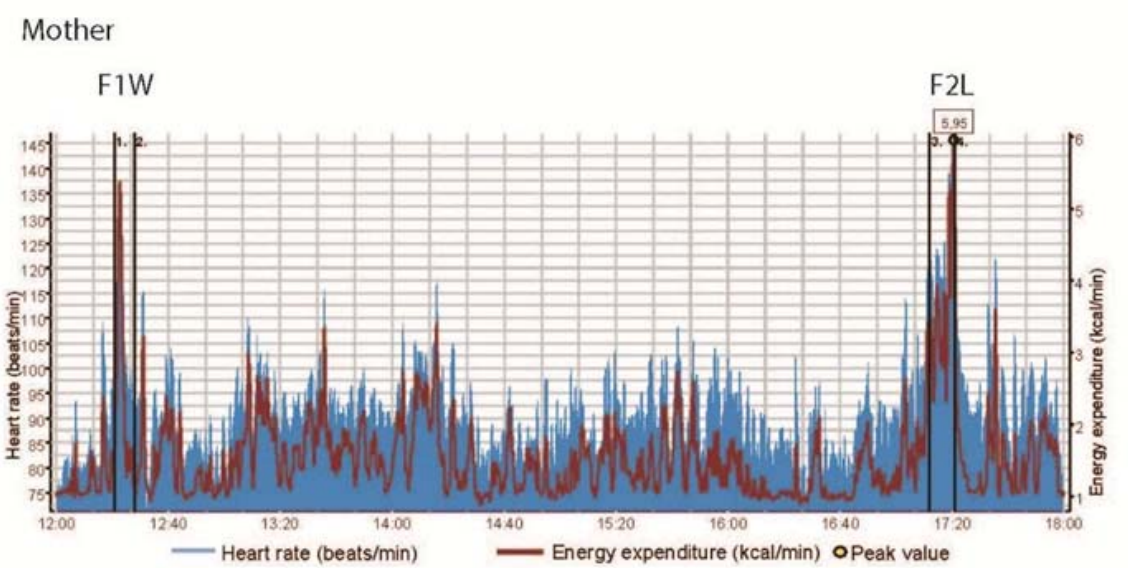

Time

Figure 2. Mother's heart rate and energy expenditure graphs during the competition. Time markers F1W- $1^{\text {st }}$ fight, won; F2L- $2^{\text {nd }}$ fight, lost.

Table 1. Heart rates and energy expenditure of both parents during the competition

\begin{tabular}{|c|c|c|c|c|c|c|}
\hline \multirow[b]{2}{*}{ Measurements } & \multicolumn{3}{|l|}{ Father } & \multicolumn{3}{|l|}{ Mother } \\
\hline & $\begin{array}{l}1^{\text {st }} \text { fight } \\
(7 \mathrm{~min})\end{array}$ & $\begin{array}{l}2^{\text {nd }} \text { fight } \\
(9 \mathrm{~min})\end{array}$ & $\begin{array}{l}\text { Competition } \\
(6 \mathrm{~h})\end{array}$ & $\begin{array}{l}1^{\text {st }} \text { fight } \\
(7 \mathrm{~min})\end{array}$ & $\begin{array}{l}2^{\text {nd }} \text { fight } \\
(9 \mathrm{~min})\end{array}$ & $\begin{array}{l}\text { Competition } \\
(6 \mathrm{~h})\end{array}$ \\
\hline Lowest HR (bpm) & 82 & 84 & 67 & 90 & 106 & 70 \\
\hline Highest HR (bpm) & 107 & 124 & 124 & 136 & 147 & 147 \\
\hline Average HR (bpm) & 96 & 102 & 81 & 106 & 122 & 91 \\
\hline Energy expenditure (kcal) & 22 & 36 & 588 & 19 & 36 & 559 \\
\hline High intensity zone (min) & & & 0 & & & 0 \\
\hline Anaerobic threshold ( $\mathrm{min}$ ) & & & 0 & & & 0 \\
\hline Aerobic zone $2(\mathrm{~min})$ & & & 0 & & & 3 \\
\hline Aerobic zone 1 (min) & & & 3 & & & 13 \\
\hline $\begin{array}{l}\text { Training effect (Firstbeat } \\
\text { defined) }\end{array}$ & & & $\begin{array}{l}1.3 \text { (facilitated } \\
\text { recovery) }\end{array}$ & & & $\begin{array}{l}2.2 \\
\text { (maintained } \\
\text { aerobic fitness) }\end{array}$ \\
\hline
\end{tabular}

Note: lowest HR measured father: 49 bpm; lowest HR measured mother: 48 bpm 
physical activity while father had 5 minutes of physical activity and 4 minutes of light physical activity. During the whole competition, mother accumulated 9 min of physical activity and 21 minutes of light physical activity while father had 5 min of physical activity and 10 minutes of light physical activity. The device recognizes physical activity as physical activity with intensity over 30\% VO2 max, and light physical activity as physical activity below $30 \%$ VO2 max. Both parents were standing by the mat, cheering but not moving or walking during both fights. As for energy expenditure, during the 7 minutes of the first fight father burned 22 and mother 19 calories. During the second fight, which lasted 9 minutes, they both burned 36 calories. In total, father burned 588 calories during the 6-hour event while mother burned 559.

\section{Emotions}

Results on the ESP-40 questionnaire are presented in Table 2 as well as Figure 3 and Figure 4. It is evident that thed father overall experienced more pleasant than unpleasant emotions before and during the competition,

Table 2. Parents' results on the ESP-40 questionnaire

\begin{tabular}{|c|c|c|c|c|c|c|c|c|}
\hline \multirow{2}{*}{ Day and competition information } & \multicolumn{4}{|c|}{ Emotions father } & \multicolumn{4}{|c|}{ Emotions mother } \\
\hline & $\mathrm{N}-$ & $\mathrm{N}+$ & $\mathbf{P +}$ & P- & $\mathrm{N}-$ & $\mathbf{N}+$ & $\mathrm{P+}$ & P- \\
\hline Wednesday & 14 & 20 & 32 & 34 & 19 & 17 & 37 & 27 \\
\hline Thursday & 12 & 18 & 35 & 35 & 37 & 31 & 19 & 13 \\
\hline Friday & 14 & 16 & 33 & 37 & 16 & 15 & 34 & 35 \\
\hline Saturday before competition & 14 & 16 & 33 & 37 & 21 & 17 & 36 & 26 \\
\hline Saturday before $1^{\text {st }}$ fight & 12 & 28 & 30 & 30 & 26 & 19 & 33 & 22 \\
\hline Saturday after $1^{\text {st }}$ fight (won) & 12 & 19 & 33 & 36 & 16 & 17 & 37 & 30 \\
\hline Saturday before $2^{\text {nd }}$ fight & 16 & 22 & 34 & 28 & 32 & 22 & 28 & 18 \\
\hline Saturday after $2^{\text {nd }}$ fight (lost) & 35 & 35 & 19 & 11 & 35 & 35 & 19 & 11 \\
\hline Saturday after competition & 35 & 35 & 19 & 11 & 39 & 29 & 17 & 15 \\
\hline Sunday & 20 & 23 & 29 & 28 & 16 & 14 & 33 & 37 \\
\hline Monday & 13 & 17 & 37 & 33 & 20 & 11 & 35 & 34 \\
\hline
\end{tabular}

$\mathrm{N}-=$ unpleasant, dysfunctional emotions; $\mathrm{N}+=$ unpleasant, functionally optimal emotions; $\mathrm{P}+=$ pleasant, functionally optimal emotions; $\mathrm{P}$ - = pleasant, dysfunctional emotions

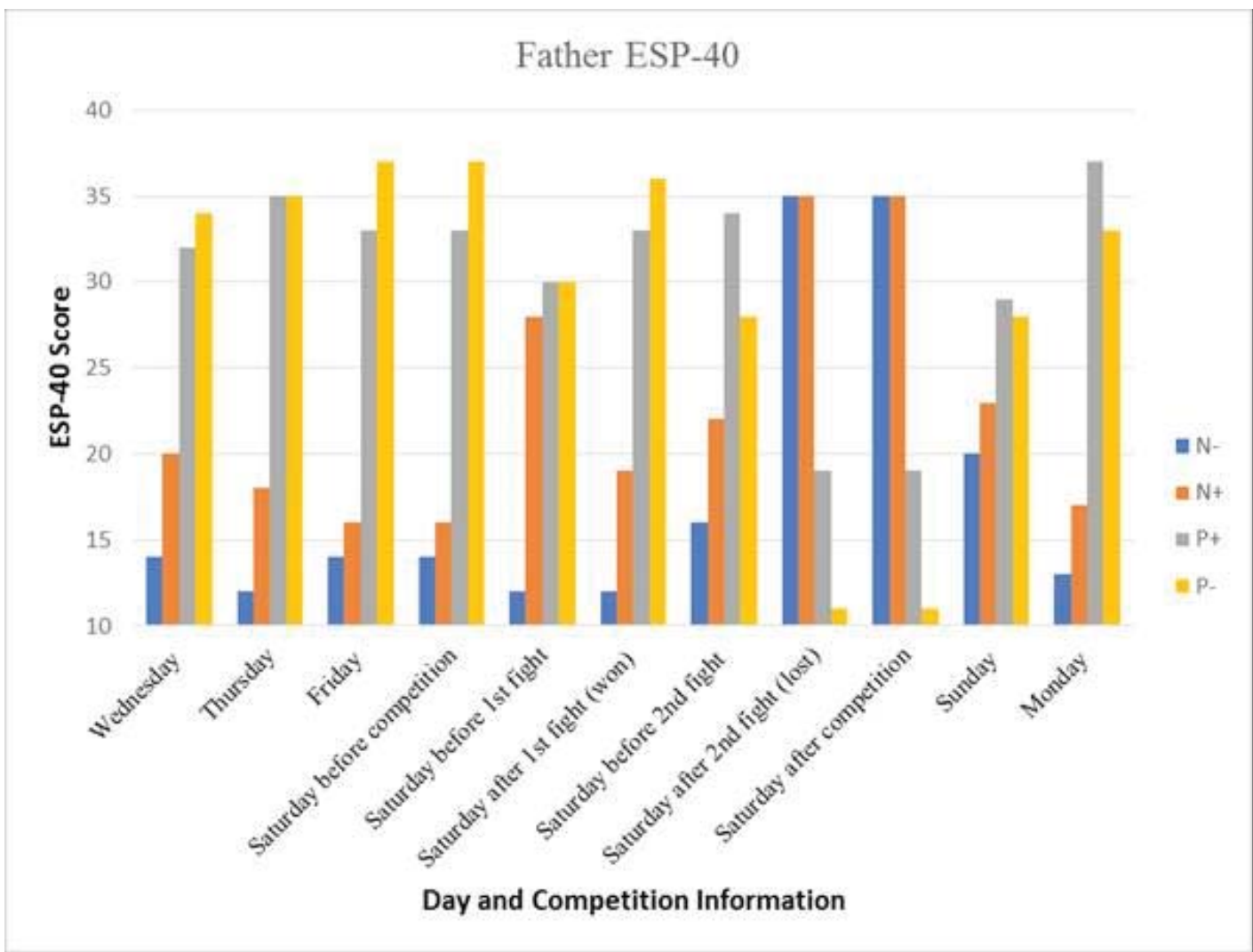

Figure 3. Father's results on the ESP-40 questionnaire. N- = unpleasant, dysfunctional emotions; N+ = unpleasant, functionally optimal emotions; $\mathrm{P}+=$ pleasant, functionally optimal emotions; $\mathrm{P}-$ = pleasant, dysfunctional emotions 


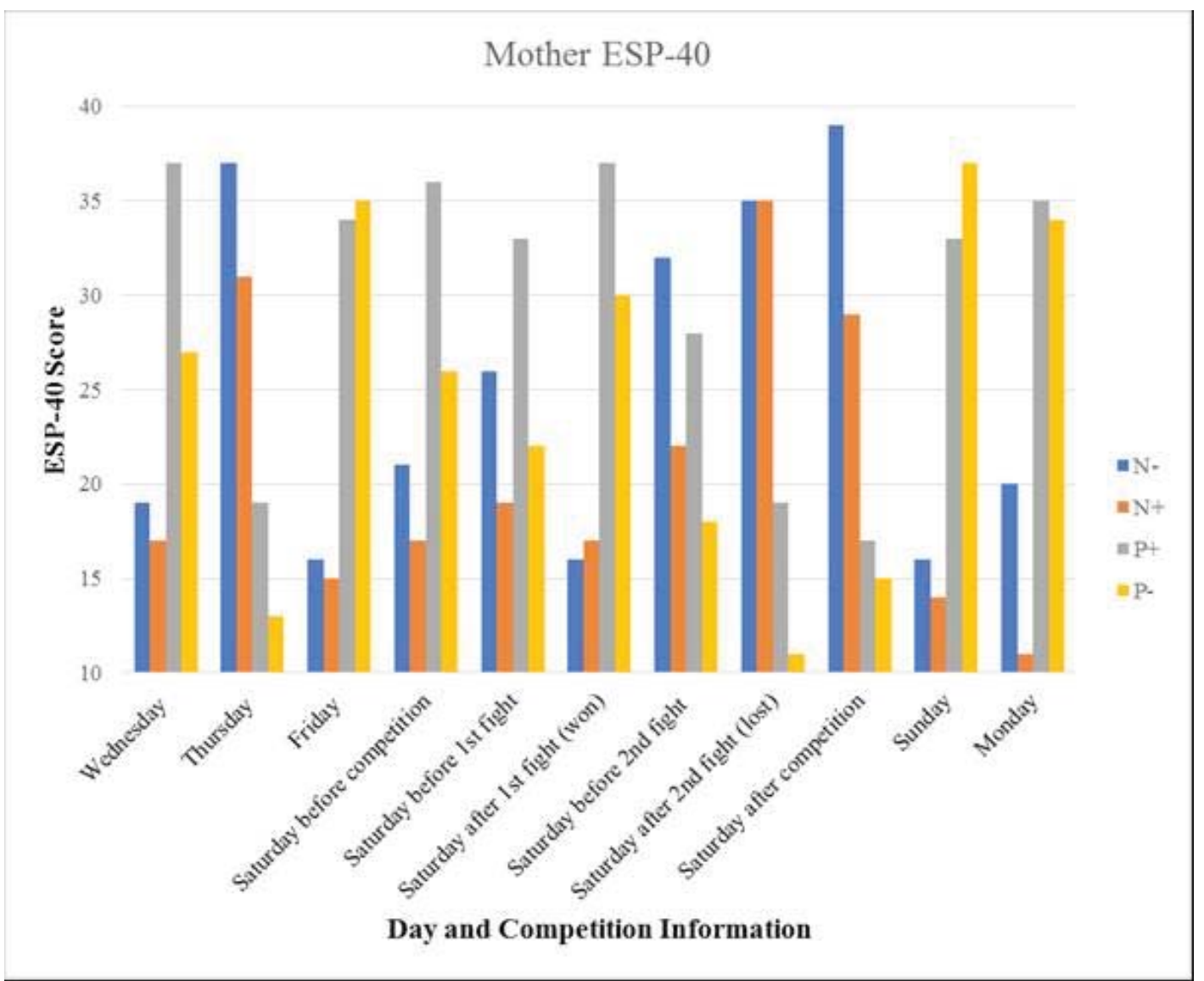

Figure 4. Mother's results on the ESP-40 questionnaire. N- = unpleasant, dysfunctional emotions; $\mathrm{N}+=$ unpleasant, functionally optimal emotions; $\mathrm{P}+=$ pleasant, functionally optimal emotions; $\mathrm{P}-$ = pleasant, dysfunctional emotions

until the end of the second fight which athlete lost and during which she got injured. At this time, father reported experiencing more unpleasant than pleasant emotions and that pattern stayed the same until the end of that day. On Sunday, after the competition, pleasant emotions became again more prominent and continued to be that way on Monday as well. More detailed analysis of the father's answers indicate that P- emotions were the most prominent on Wednesday, Friday and Saturday before the competition, followed by $\mathrm{P}+$ emotions. On Thursday and on Saturday before the first fight $\mathrm{P}$ - and $\mathrm{P}+$ emotions were equally present. However, even though pleasant emotions were still most prominent before the first fight on Saturday, $\mathrm{N}+$ emotions were more present during this time compared to all previous measurements. After athlete won the first fight, father's emotional profile was again similar to the ones he had before. Furthermore, before the second fight, father for the first time experienced more $\mathrm{P}+$ than $\mathrm{P}$ - emotions, and then both pleasant emotions dropped after the fight, with $\mathrm{P}$ - being the least prominent and unpleasant emotions $(\mathrm{N}+$ and $\mathrm{N}-$ ) being the most prominent. This again changed on Sunday and Monday but with $\mathrm{P}+$ emotions being the most prominent, followed by $\mathrm{P}-$, and $\mathrm{N}$ - again becoming the least prominent.

The mother's emotional profile changed more frequently than the father's emotional profile during the 11 measurements. She reported feeling more pleasant than unpleasant emotions on Wednesday, 3 days before the competition, with $\mathrm{P}+$ emotions being the most and $\mathrm{N}$ - the least prominent. However, this changed two days before the competition, when she reported more unpleasant than pleasant emotions, predominantly N-, with P- being the least prominent. This again changed day before competition with pleasant emotions being higher than unpleasant and this time P- the most prominent. On Saturday, before the competition, this changed again and now $\mathrm{P}+$ emotions were the most prominent, followed by P-. However, just before the first fight the second most prominent emotions were $\mathrm{N}$ - following the $\mathrm{P}+$ which was still the most prominent. This again changed after athlete won the first fight. $\mathrm{P}+$ emotions were again the most prominent, followed by P-. However, for the first time $\mathrm{N}$ - emotions were the least prominent. Furthermore, before second fight $\mathrm{N}$ - emotions became the most prominent, followed by $\mathrm{P}+$ emotions and with $\mathrm{P}$ - being the least prominent. Unpleasant emotions were the most prominent after the second fight which athlete lost and got injured. Here, again, P- emotions were the least prominent. The $\mathrm{N}$ - emotions continued to rise on Saturday after the competition, followed by $\mathrm{N}+$ emotions and with P- again being the least prominent. Again, mother's emotional profile changed on Sunday, day after the competition, when pleasant emotions became again more prominent than unpleasant, with P- being the most 
and $\mathrm{N}+$ the least prominent. Pleasant emotions stayed higher than unpleasant two days after competition but this time $\mathrm{P}+$ were the most prominent and $\mathrm{N}+$ again the least prominent.

Overall competition experience

On the open-ended questionnaire about the overall experience, which parents filled at the end of the competition day, father answered: "Today was a day with lots of nervousness and uncertainty about the outcome of each fight. Despite good fights, we were stopped with judge's decision and with that my daughter showed she didn't come here on a field trip because she made one of the best competitors in her category struggle until the end. Maybe I could be satisfied at the end, but the whole story was ruined with going to the hospital and doing the RTG of the finger which was injured during the last fight."

Mother's answer was: "First there was a fear from first fight. After that there was a second fight where opponent was very strong so my daughter lost on golden score. She injured her finger. Overall, I'm sad because of the injury. I know that she can do it, that she gave her best and become a great fighter. I feel a little sad but it will pass."

These answers indicate father experiencing nervousness and uncertainty about the outcome of the fights with injury being the most prominent experience which "ruined" the whole experience for him. Mother reported experiencing fear for the first fight and sadness because of the injury. Even though it wasn't specifically mentioned, from both answers it can be seen that they are proud of their daughter and how she fought.

Stress, anxiety, depression and coping. From the results on the DASS-21 questionnaire (Table 3) it be concluded that mother reported experiencing more stress than father did.

Table 3. Parent results on the DASS-21 and Coping questionnaire

\begin{tabular}{lll}
\hline Constructs & Father & Mother \\
\hline Stress & 5 & 8 \\
Anxiety & 1 & 1 \\
Depression & 4 & 3 \\
Negotiating & 3 & 2.5 \\
Planning & 3 & 4 \\
Active adapting & 2.75 & 3.5 \\
Reinterpretation & 2.75 & 3.25 \\
Humour & 2.75 & 2.75 \\
Social support & 3.25 & 3 \\
Expressing emotions & 2.75 & 2.25 \\
Wishful thinking & 3 & 2.75 \\
Avoiding & 2.5 & 3.25 \\
Passivization & 3 & 2.5 \\
Fatalism/religion & 2.5 & 2.5 \\
Smoking/alcohol & 1 & 1 \\
Exercising & 3 & 3 \\
\hline
\end{tabular}

Father reported feeling slightly more depression than mother but these results were both low. Both reported their anxiety levels as minimal. Figure 5 and Figure 6 shows that father slept less than mother and thus recovered less, especially on Friday and Saturday night, which resulted in his body resources dropping below starting level on Saturday evening and even more on Sunday evening. However, he recovered better on Sunday night and ended up measurement with body resources higher than starting level. Mother's body resources curve were similar to each other two days before the competition and then started to increase on Sunday evening resulting in them being at the highest point on Sunday morning and overall ending up increased compared to the starting point.

Results on the Coping with stress scale (Table 3) indicate father using social support the most as his coping strategy, followed by negotiating, planning, wishful thinking, passivization and exercising. Mother used planning most to cope with the stressors, followed by active adapting, reinterpretation and avoiding. Mother used more planning, active adapting, reinterpretation and avoiding, as well as less social support, expressing emotions, wishful thinking and passivization than father did.

\section{Discussion}

In this study, the goal was to document cardiovascular, metabolic and emotional reactions of sport parents before, during and after their child's competition taking into consideration their expectations for the event. The mixed-methods approach was used, similar to the one used in our previous pilot study on sport parents [20]. To further expand the existing research base in this area, we quantitatively measured parent's cardiovascular, metabolic and emotional reactions, levels of stress, anxiety and depression as well as coping strategies they used to cope with stress before, during and after their daughter's National Championship in taekwondo. In addition, we qualitatively investigated their expectations for the event as well as asked them about their overall experience after the event. Previous research indicates that parents have vital and complex roles before, during and after their child's sport competition [37-39]. In this research we wanted to expand the existing literature by investigating their thoughts, reactions, level of stress and ways of coping with their child's competition.

Cardiovascular reactions and thus energy expenditure of mother and father was somewhat similar in pattern but differed in intensity with mother experiencing stronger reactions. Both parents were the most physiologically engaged during the fights. Father's answers to the openended question about his expectations suggest him having task-goal orientation while mother put more emphasis on winning the fights thus showing ego-goal orientation. In our previous study [20], task-oriented mother had the cardiovascular reactions similar to both parents in this study since she was the most physiologically engaged during the fights. Although in this study we didn't confirm the same pattern of ego-goal orientation parent 


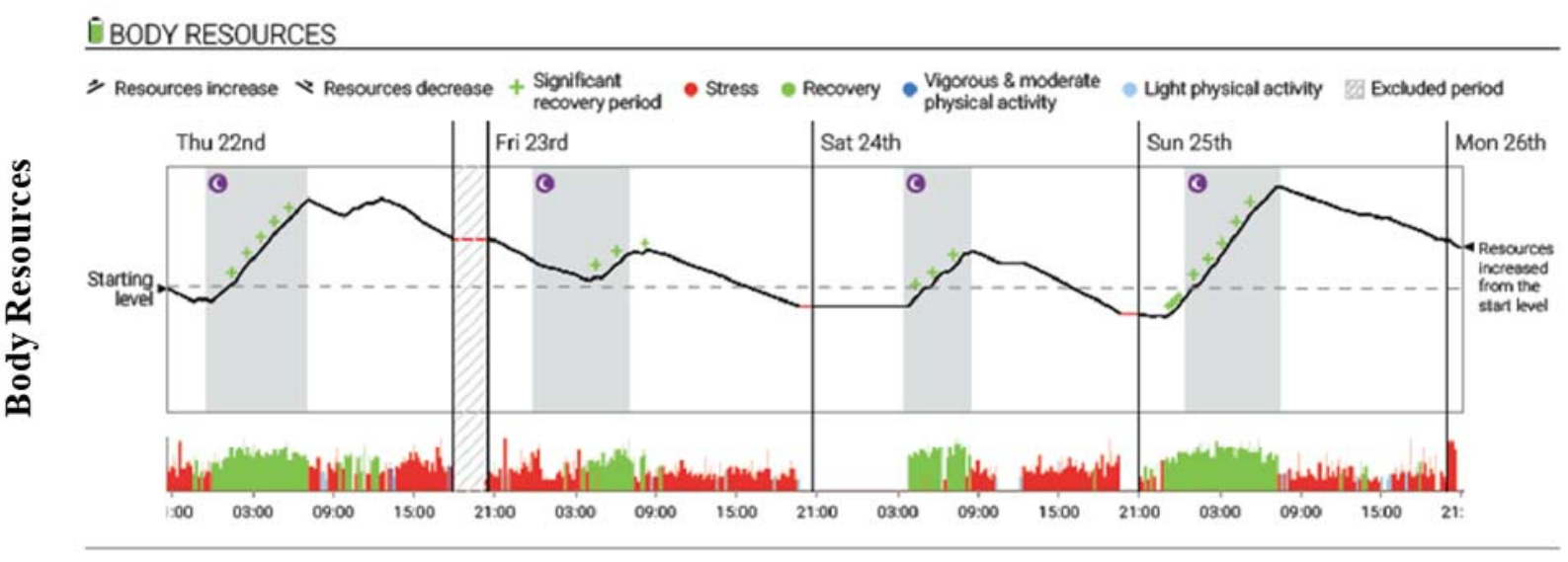

Time

Figure 5. Overview of father's stress measurements during all measurement days

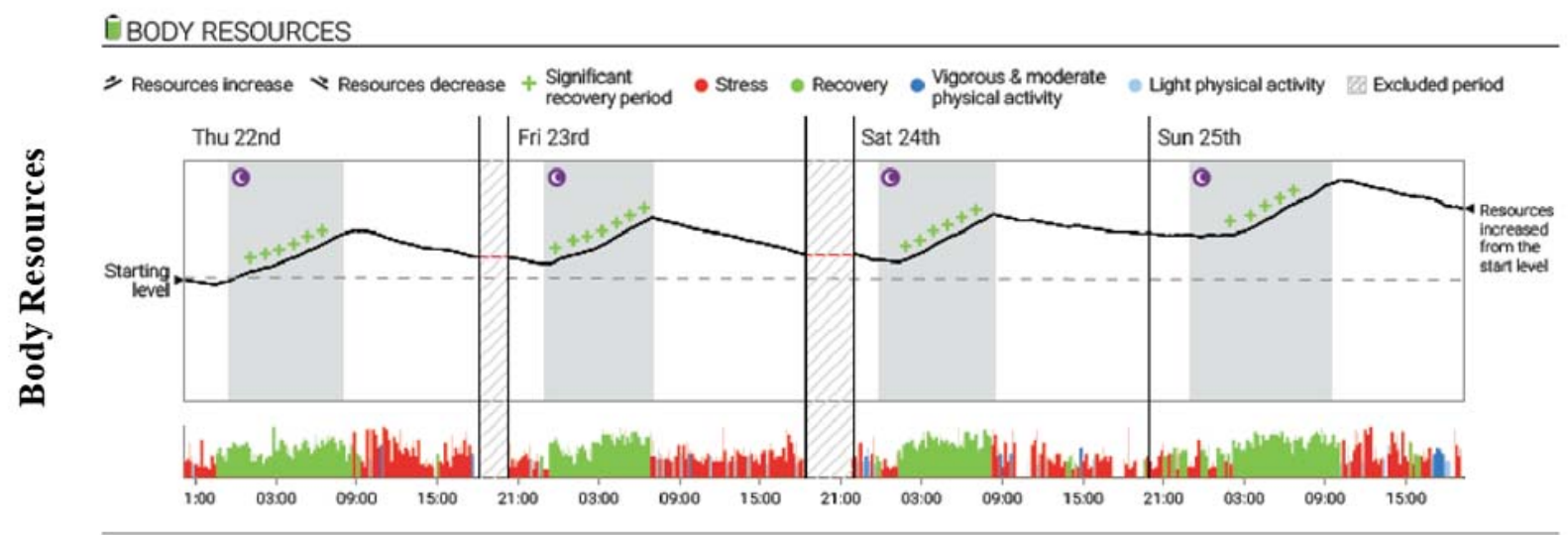

Time

Figure 6. Overview of mothers' stress measurements during all measurement days

reacting clearly to the outcome of the fights like we did in our previous study, mother's stronger reaction at the beginning of the first fight and decline in reaction towards the end of that fight, which her daughter was winning, suggests her reactions also depending on the outcome. Furthermore, during the second fight both parents in this study had almost the same reaction pattern, with the highest physiological activity recorded toward the end of very close fight where winner wasn't decided up until the very end. Also, their daughter got injured during the second fight which influenced parent's experience of the whole event as they both mentioned it in their overall reflection question answered at the end of the competition day. It is impossible to distinguish their cardiovascular and metabolic reactions for the fight from their reaction on the injury from the data we have collected so more research is needed to clarify these findings.

To further clarify the cardiovascular and metabolic data, in this study we collected parent's emotional reactions 11 times before, during and after the competition including before and after each fight. Results suggest father experiencing overall more pleasant than unpleasant emotions with only exception being after the second fight and at the end of the competition day, when it was vice versa. This shift of emotions could be due to the injury but also the negative outcome of the fight which was lost. Mother's emotional profile changed 8 times during 11 times measurement. She reported feeling unpleasant emotions more frequently than father did although her experience was also overall more pleasant than unpleasant. She experienced three big increases in $\mathrm{N}$ - emotions, one two days before the competition, second one just before the second fight and the third one after the competition was over when these emotions become the most prominent. Same shift as with father's emotions happened after the second fight was lost and her daughter got injured. At that time, she also reported feeling more unpleasant than pleasant emotions and that pattern also continued until the end of the competition day with an increase in $\mathrm{N}$ - emotions on Saturday evening compared both to all of her previous measurements and father's $\mathrm{N}$ - emotions at the same measurement point. Furthermore, mother reported experiencing greater level of stress than father. Keegan and colleagues [40] found that parents emotional reactions and behaviours before their child's sport competition can have a great influence on young athlete. Management of their own emotional reactions is recognized as important skill sport parents 
should develop to successfully support their child's sport participation [16]. Investigating their emotional reactions before, during and after the competition can help further expand the knowledge from the few existing research studies on parents' emotions in sport [6, 29]. Previous research on parents in sport suggests that their involvement is influenced by numerous factors, including their expectations as well as goals for their child's sport participation [41]. The results in our study are in line with finding that task-orientation is positively correlated with positive emotions and ego-orientation with negative emotions [23, 24]. This indicates parent's goals as well as their goal orientation is important area for further investigation.

This is the first research that investigated sport's parents experiences few days before, during and few days after the competitions and also the first one which used technology to monitor their stress and recovery. Results in this study showed that father had less sleep and recovered more poorly compared to the mother which resulted in his Firstbeat reported body resources dropping below the starting level on the evening of the competition day and even more the day after. On the contrary, mother's body resources never dropped below the starting point. He also reported feeling slightly more depressed than mother although both of their results were low. These findings suggest there is a need to include more variables into investigating and explaining sport parent's experiences before, during and after their child's sport competition, one of them being the amount and quality of sleep. Only more in detail research focusing on these variables can clarify their potential importance.

Finally, results of this study suggest both parents using numerous coping strategies to cope with this experience. This is in line with findings from study conducted by Burgess and colleagues [11] who suggested that sport parents often use multiple coping strategies in combination. In our study, father predominantly used social support while mother mostly used planning. This is in line with study conducted by Harwood and colleagues [6] who reported tennis players parents using mostly mastery coping strategies (e.g. communicating with a child, information seeking, time management) followed by internal regulation (e.g. cognitive reappraisal, seeking emotional support, behavioural avoidance) to deal with competitive stressors. It was previously suggested that people rarely cope with stress isolated from others and that coping should be investigated as social phenomenon [42]. Thus, we suggest including dyadic coping research into investigating sport parents' experiences since authors in dyadic coping area often put the emphasis on close relationships [43-45].

We suggest future studies on more parents are worth conducting. If the measurements are held during the number of days before and after the competition, we suggest that giving the parents some kind of diary with open-ended questions to answer every day would help better understand their experiences. Diaries are often used in stress research on coaches and athletes [46, 47] and could provide valuable information we missed in this study.

\section{Conclusion}

It is important to document and understand parent's experiences during the sport events of their children to enhance their well-being but also help them provide adequate support to their child. Sport competitions can be very demanding for the parents and this research provides an insight into their physiological and psychological reactions to the event. Future studies with more participants are necessary to put these results into perspective.

\section{Conflicts of Interest}

The authors declare no conflict of interest.

\section{References}

1. Brustad RJ. Who will go out and play? Parental and psychological influences on children's attraction to physical activity. Pediatric Exercise Science. 1993;5(3):210-23. https://doi.org/10.1123/pes.5.3.210

2. Brustad RJ. Attraction to physical activity in urban schoolchildren: Parental socialization and gender influences. Research Quarterly For Exercise And Sport. 1996;67(3):316-23. https://doi.org/10.1080/02701367.1996.10607959

3. Wuerth S, Lee MJ, Alfermann D. Parental involvement and athletes' career in youth sport. Psychology of sport and Exercise. 2004;5(1):21-33. https://doi.org/10.1016/S1469-0292(02)00047-X

4. Dorsch TE, Smith AL, McDonough MH. Parents' perceptions of child-to-parent socialization in organized youth sport. JournalofSportandExercisePsychology.2009;31(4):444-68. https://doi.org/10.1123/jsep.31.4.444

5. Harwood C, Knight C. Stress in youth sport: A developmental investigation of tennis parents. Psychology of Sport and Exercise. 2009;10(4):447-56. https://doi.org/10.1016/j.psychsport.2009.01.005
6. Harwood C, Thrower S, Slater MJ, Didymus F, Frearson L. Advancing Our Understanding of Psychological Stress and Coping Among Parents in Organized Youth Sport. Frontiers in psychology. 2019;10: 1600. https://doi.org/10.3389/fpsyg.2019.01600

7. Lazarus RS, Folkman S. Stress, Appraisal and Coping. New York, NY: Springer; 1984.

8. Lazarus RS. Emotion and adaptation. New York, NY: Oxford University Press; 1991.

9. Lazarus RS. Stress and Emotion: A New Synthesis. New York, NY: Springer; 1999.

10.Lazarus RS. How emotions influence performance in competitive sports. The Sport Psychologist. 2000;14(3):229-52. https://doi.org/10.1123/tsp.14.3.229

11.Burgess NS, Knight CJ, Mellalieu SD. Parental stress and coping in elite youth gymnastics: an interpretative phenomenological analysis. Qualitative Research in Sport, Exercise and Health. 2016;8(3):237-56. https://doi.org/10.1080/2159676X.2015.1134633

12.Nicholls AR, Taylor NJ, Carroll S, Perry JL. The development of a new sport-specific classification of 
coping and a meta-analysis of the relationship between different coping strategies and moderators on sporting outcomes. Frontiers in psychology. 2016;7: 1674. https://doi.org/10.3389/fpsyg.2016.01674

13.Crocker PR, Graham TR. Coping by competitive athletes with performance stress: Gender differences and relationships with affect. The Sport Psychologist. 1995;9(3):325-38. https://doi.org/10.1123/tsp.9.3.325

14.Didymus FF. Olympic and international level sports coaches' experiences of stressors, appraisals, and coping. Qualitative Research in Sport, Exercise and Health. 20179(2):214-32. https://doi.org/10.1080/2159676X.2016.1261364

15.Dugdale JR, Eklund RC, Gordon S. Expected and unexpected stressors in majorinternational competition: Appraisal, coping, and performance. The Sport Psychologist. 2002;16(1):20-33. https://doi.org/10.1123/tsp.16.1.20

16.Harwood CG, Knight CJ. Parenting in youth sport: A position paper on parenting expertise. Psychology of Sport and Exercise. 2015;16:24-35. https://doi.org/10.1016/j.psychsport.2014.03.001

17.Goldstein DS. Stress-induced activation of the sympathetic nervous system. Bailliere's Clinical Endocrinology and Metabolism. 1987;1(2):253-78. https://doi.org/10.1016/S0950-351X(87)80063-0

18. Castagna C, Impellizzeri FM, Chaouachi A, Bordon C, Manzi $\mathrm{V}$. Effect of training intensity distribution on aerobic fitness variables in elite soccer players: a case study. The Journal of Strength \& Conditioning Research. 2011;25(1):66-71. https://doi.org/10.1519/JSC.0b013e3181 fef3d3

19.Plews DJ, Laursen PB, Kilding AE, Buchheit M. Heartrate variability and training-intensity distribution in elite rowers. International Journal of Sports Physiology and Performance. 2014;9(6):1026-32. https://doi.org/10.1123/ijspp.2013-0497

20.Lochbaum M, Prosoli R, Barić R. Cardiovascular and Energy Requirements of Parents Watching Their Child Compete: A Pilot Mixed-Methods Investigation. Pedagogics, Psychology, Medical-Biological Problems of Physical Training and Sports. 2017; 21(6):279-84. https://doi.org/10.15561/18189172.2017.0604

21.Nicholls JG. Achievement motivation: Conceptions of ability, subjective experience, task choice, and performance. Psychological Review. 1984;91(3):328-46. https://doi.org/10.1037/0033-295X.91.3.328

22.Nicholls JG. The competitive ethos and democratic education. Cambridge, M.A.: Harvard Uiiversity Press; 1989.

23.Harwood CG, Keegan RJ, Smith JM, Raine AS. A systematic review of the intrapersonal correlates of motivational climate perceptions in sport and physical activity. Psychology of Sport and Exercise. 2015;18:9-25. https://doi.org/10.1016/j.psychsport.2014.11.005

24.Lochbaum M, Zazo R, Kazak Çetinkalp Z, Wright T, Graham KA, Konttinen N. A meta-analytic review of achievement goal orientation correlates in competitive sport: A follow-up to Lochbaum et al.(2016). Kinesiology: International Journal of Fundamental and Applied Kinesiology. 2016;48(2):159-73. https://doi.org/10.26582/k.48.2.15

25.Hogue CM, Fry MD, Fry AC. The differential impact of motivational climate on adolescents' psychological and physiological stress responses. Psychology of Sport and Exercise. 2017;30:118-27. https://doi.org/10.1016/j.psychsport.2017.02.004

26. Gould D, Lauer L, Rolo C, Jannes C, Pennisi N. Understanding the role parents play in tennis success: a national survey of junior tennis coaches. British Journal of Sports Medicine. 2006;40(7):632-6. https://doi.org/10.1136/bjsm.2005.024927

27.Knight CJ, Boden CM, Holt NL. Junior tennis players' preferences for parental behaviors. Journal of Applied Sport Psychology. 2010;22(4):377-91. https://doi.org/10.1080/10413200.2010.495324

28. Wiersma LD, Fifer AM. "The schedule has been tough but we think it's worth it": The joys, challenges, and recommendations of youth sport parents. Journal of Leisure Research. 2008;40(4):505-30. https://doi.org/10.1080/00222216.2008.11950150

29.Omli J, LaVoi NM. Emotional experiences of youth sport parents I: Anger. Journal of Applied Sport Psychology. 2012;24(1):10-25. https://doi.org/10.1080/10413200.2011.578102

30.Lauer L, Gould D, Roman N, Pierce M. Parental behaviors that affect junior tennis player development. Psychology of Sport And Exercise. 2010;11(6):487-96. https://doi.org/10.1016/j.psychsport.2010.06.008

31.Hanin YL. Emotions in sport. Champaign, IL:Human Kinetics; 2000. https://doi.org/10.5040/9781492596233

32.Hanin YL. From anxiety to performance-related emotions in top-level sport. Kalokagathia. 2010;2:59-76. https://doi.org/10.1037/e538952013-008

33. Bosnar K, Prot S. Emotion State Profile (ESP-40). Unpublished translation to Croatian; 2010.

34.Lovibond SH,Lovibond PF.Manual for the DepressionAnxiety \&Stress Scales.2nded. Sydney:Psychology Foundation; 1995. https://doi.org/10.1037/t01004-000

35.Norton PJ. Depression Anxiety and Stress Scales (DASS-21): Psychometric analysis across four racial groups. Anxiety, Stress, and Coping. 2007;20(3):253-65. https://doi.org/10.1080/10615800701309279

36.Buško V. Transactional stress and coping theory in accounting for psychological states measures. Medicinski Glasnik. 2007; 4(2):63-70

37.Elliott SK, Drummond MJ. Parents in youth sport: what happens after the game? Sport, Education and Society. 2017;22(3):391-406. https://doi.org/10.1080/13573322.2015.1036233

38.Knight CJ, Neely KC, Holt NL. Parental behaviors in team sports: How do female athletes want parents to behave? Journal of Applied Sport Psychology. 2011;;23(1):76-92. https://doi.org/10.1080/10413200.2010.525589

39.Omli J, Wiese-Bjornstal DM. Kids speak: Preferred parental behavior at youth sport events. Research Quarterly for Exercise and Sport. 2011;82(4):702-11. https://doi.org/10.1080/02701367.2011.10599807

40.Keegan R, Spray C, Harwood C, Lavallee D. The motivational atmosphere in youth sport: Coach, parent, and peer influences on motivation in specializing sport participants. Journal Oo Applied Sport Psychology. 2010;22(1):87-105. https://doi.org/10.1080/10413200903421267

41.Knight CJ, Dorsch TE, Osai KV, Haderlie KL, Sellars PA. Influences on parental involvement in youth sport. Sport, Exercise, and Performance Psychology. 2016;5(2): 161. https://doi.org/10.1037/spy0000053

42.Cutrona CE, Gardner KA. Stress in Couples: The Process of Dyadic Coping. In: Vangelisti AL, Perlman D, editors. The Cambridge handbook of personal relationships. New York: Cambridge University Press; 2006. P. 501-15. https://doi.org/10.1017/CBO9780511606632.028

43.Berg CA, Upchurch R. A developmental-contextual model of couples coping with chronic illness across the adult life span. Psychological Bulletin. 2007;133(6): 920. https://doi.org/10.1037/0033-2909.133.6.920 
44.Bodenmann G. A systemic-transactional conceptualization of stress and coping in couples. Swiss Journal of Psychology.1995; 54(1):34-49.

45.Coyne JC, Smith DA. Couples coping with a myocardial infarction: a contextual perspective on wives' distress. Journal of Personality and Social Psychology. 1991;61(3): 404. https://doi.org/10.1037/0022-3514.61.3.404

46.Didymus FF, Fletcher D. Getting to the heart of the matter: A diary study of swimmers' appraisals of organisational stressors. Journal of Sports Sciences. 2012;30(13):1375-85. https://doi.org/10.1080/02640414.2012.709263

47.Levy A, Nicholls A, Marchant D, Polman R. Organisational stressors, coping, and coping effectiveness: A longitudinal study with an elite coach. International Journal of Sports Science \& Coaching. 2009;4(1):31-45. https://doi.org/10.1260/1747-9541.4.1.31

\section{Information about the authors:}

Rebeka Prosoli; http://orcid.org/0000-0001-6571-6200; rebeka.prosoli@kif.hr; Faculty of Kinesiology, University of Zagreb; Zagreb, Croatia.

Marc Lochbaum; (Corresponding Author); http://orcid.org/0000-0001-7640-7075; marc.lochbaum@ttu.edu; Department of Kinesiology and Sport Management, Texas Tech University; Lubbock, TX, USA. ; Education Academy, Vytautas Magnus University; Kaunas, Lithuania.

Renata Barić; http://orcid.org/0000-0003-2614-673X; renata.baric@kif.hr; Faculty of Kinesiology, University of Zagreb; Zagreb, Croatia..

Cite this article as:

Prosoli R, Lochbaum M, Barić R.. Parents at the sport competition: How they react, feel and cope with the event. Pedagogy of Physical Culture and Sports, 2021;25(2):114-124.

https://doi.org/10.15561/26649837.2021.0206

This is an Open Access article distributed under the terms of the Creative Commons Attribution License, which permits unrestricted use, distribution, and reproduction in any medium, provided the original work is properly cited (http://creativecommons.org/licenses/by/4.0/deed.en).

Received: 10.09.2020

Accepted: 14.10.2020; Published: 30.04.2021 